\title{
ASPECTOS DA CORRESPONDÊNCIA ENTRE JORGE DE SENA E JOSÉ RÉGIO
}

Horácio Costa*

\begin{abstract}
RESUMO: A extensa correspondència entre José Régio, fundador do movimento da "presença", e Jorge de Sena, um dos mais significativos intelectuais portugueses de meados do século XX, oferece subsidios para a compreensão da dinâmica intergeneracional no contexto da poesia portuguesa depois do Modernismo. O presente ensaio focaliza, a partir dela, as diferenças de horizonte estético e informacional entre os corresponsais e assinala, no âmbito da literatura portuguesa moderna, uma forma de trans. missão dos valores literários que embasam a relaçāo entre Régio e Sena, na qual o peso da palavra do mais velho prenuncia a reaçāo do mais jovem, apesar das contraposiçōes deste, expressas numa carta nāo enviada, cujo teor se refere à problemática política advinda do movimento militar de 1964 no Brasil. Assim sendo, o telāo de fundo da história recente brasileira e portuguesa impōe-se como instāncia privilegiada para a compreensāo e análise da relaçāo entre José Régio e Jorge de Sena e entre os presencistas e a geraçāo posterior, crítica dos mesmos.
\end{abstract}

PALAVRAS-CHAVE: Poesia portuguesa moderna; vínculos intergeneracionais na intelectualidade portuguesa; relações politico-culturais entre Portugal e Brasü; análise epistolográfica.

* Universỉdade de São Paulo - USP. 
a longo de 23 anos, de 1946 a 1969, José Régio e Jor-
ge de Sena trocaram um extenso intercâmbio postal. No levantamento de Mécia de Sena, que deu origem ao volume por ela organizado e simplesmente intitulado Correspondência (Lisboa: Imprensa Nacional, Casa da Moeda, 1986), constam 56 envios de Sena para Régio, e cinqüenta deste para aquele, distribuídos em cartas propriamente ditas - 49 escritas por Sena e 47 por Régio -. alguns bilhetes postais (seis escritos pelo primeiro e apenas um pelo segundo) e um cartāo, também remetido por Sena a Régio. A correspondência de Sena inclui cartas datilografadas - dez no total -; a de Régio é totalmente manuscrita. No volume organizado pela viưva de Jorge de Sena, reproduz-se também uma carta escrita por seu marido em seu auto-exílio brasileiro e não enviada a Régio, que se reveste, por isso mesmo, de especial interesse e à qual voltarei mais adiante, bem como as respostas parciais de Régio a um longo questionário sobre sua obra mandado por Sena, e que daria as bases para a escritura de um artigo deste sobre ela, jamais concluído; desde já, para essas respostas chamo a atenção dos estudiosos da obra regiana, uma vez que aqui não serāo enfocadas.

Como não podia deixar de ser, tal intercâmbio longo e volumoso constitui um lugar privilegiado para a consideração de dois criadores da literatura portuguesa moderna, tanto no que revelam sobre as suas personalidades, como pelo que guardam sobre a vida literária da e na época. Além disso, apesar de Régio e Sena serem dois individuos com características, gostos e horizontes especificos, a relação postal entre ambos pode assumir um valor referencial, se lida com um ponto de vista generalizador que privilegie a historiografia da literatura, podendo indicar as zonas de conflito e comunhão entre a geração da presença e a posterior. Além de tudo isso, ainda, a epistolografia Régio/Sena tem interesse para o estudo - ou, mais do que isto: para a compreensão - da relação entre dois autores com interesses literários e estéticos semelhantes, sob a luz da exemplaridade - positiva ou negativa - que a figura do 
mais velho pode significar para o mais moço; a figura daquele como uma espécie de modelo literário para o bem ou para o mal, o que me leva neste momento a recordar, ainda que en passant, a mecãnica da anxiety of influence, conceito cunhado por Harold Bloom. Minha preocupação, devo dizer, não é com a petite histoire, um risco sempre presente quando se trata de processar qualquer epistolografia que inclua tanto informações de cunho profissional como pessoal, tanto de referências às perpétuas quezilias literárias quanto às da ordem mais subjetiva. Ao contrário, preocupo-me em estudar como se dá - ou melhor, como se dava - a transmissão de uma certa sensibilidade literária intergeracionalmente. Numa época em que cada vez menos se corresponde por meio do papel e - luxo supino! - pelo manuscrito, na qual o intercâmbio crescentemente virtual torna-nos proclives à desmemória da falta do documento, é com nostalgia e com relativa inveja que me debruço sobre a relação postal entre José Régio e Jorge de Sena.

Vale dizer que há muitos veios a serem explorados nessa correspondência exemplar. Aqui nos deteremos em apenas três aspectos: primeiro, salientar nela alguns trechos relacionados com a concepção da obra literária e da linguagem poética; segundo, e como. não podia deixar de ser em se tratanito de um intercāmbio postal que tem tanto de profissional como de subjetivo, avaliar a imagem evolutiva de cada um deles com relação ao outro; finalmente, e em consonāncia com este último aspecto, recuperar as críticas de Sena a Régio na referida carta não enviada. Em poucas palavras, aqui se tentará analisar, ainda que sumariamente, a correspondência entre ambos num arco que vai das considerações estéticas às éticas.

Com relação ao primeiro aspecto, Régio, já em carta de 26 de fevereiro de 1946, busca estabelecer um terreno comum com Sena, considerando a concepção da obra literária. Este havia escrito uma crítica sobre Histórias de mulheres que impressiona muito favoravelmente ao autor delas, porque parece se pautar pelo que considera "o essencial, o importante, o significativo" no livro, ao contrấrio 
de outras críticas "sô preocupadas com a superficialidade tếcnícá, e apostadas em julgar livros que são sentidos como se foram exercicios literários" (op. cit., p. 38-9). Vislumbramos aqui um horizonte de imanentismo da "coisa" literária, uma concepção que não a vê redutivel a uma crítica "objetiva", um intuito de preservação da "artisticidade" da obra; por outro lado, tal concepção parece excluir qualquer sentido de experimentalismo, seja ele propriamente literário ou literário-crítico. A julgar pelo trecho, para Régio a peça crítica tanto melhor será quanto maior for a sua proximidade, sua empatia para com o texto criticado. Não temos uma resposta direta de Sena a este trecho, nem a tal visão, no ãmbito da sua correspondência com Régio.

Temos, sim, um outro trecho de Régio, em carta escrita mais de oito anos depois (24 de novembro de 1950), na qual ele critica dois livros de Sena (Pedra filosofal e O indesejado). Passada quase uma década, jả a distância da linguagem literária de ambos os autores, e indiretamente, entre ambas as gerações, torna-se patente quando Régio aponta a Sena que "o problema que tanto um como outro [desses livros] logo põem é o da sua difícil comunicabilidade. Guer-me parecer que nenhum autor, entre nós, atingiu tal intelectualização e tal hermetismo [...]" (p. 59). Açulado pela dupla categorizaçâo, Sena responde incontinenti (26 de novembro de 1950), e formula um tanto abruptamente a Régio três questões: "[...] não serả um parti-pris demasiado de geração, de época, de formação espiritual, que o leva a considerar-me hermético? Naquele sentido em que achamos hermético ou destituído de valor significativo aquilo que é significação dialeticamente distante de nós?", finalizando o trecho por perguntar-lhe se tal parti-pris "Não será um daqueles [...] que uma pessoa como V. é das raras entre nós com obrigação e possibilidade de superar?" (p. 60). A esse trio de perguntas incômodas somam-se várias outras que se apresentam ao leitor atual como uma autodefesa e autodefinição estética de Sena, em franca contraposição com o que percebe serem as bases critica e estética do 
mais velho. Depois de mencionar uma notável corrente de nomes "herméticos" ou "intelectualistas" de duas gerações internacionais, a correspondente à de Régio e à sua própria - entre eles, Eliot e Pound e Auden e Dylan Thomas, no que faz gala de suas leituras inglesas -, Sena procura estabelecer a diferença entre si e Régio, dizendo que "há neles" - isto é, nesses poetas - "toda uma experiência espiritual de post-simbolismo, de surrealismo que homens como V. conhecem como informação cultural, mas não vivem como actividade do espírito poético" (p. 61).

Régio não polemiza e não responde aos protestos de Sena, que soam como uma verdadeira interpelação. Prudentemente, havia dito em sua carta que teria gostado de tratar esses tópicos ao vivo e talvez o tenha feito; temos a impressão de que, com o tempo, cada vez comportava-se com maior cuidado com Sena, dono de notória susceptibilidade, comparável apenas, talvez, com sua grande inteligência, que Régio, diga-se de passagem, não perde oportunidade de realçar em suas cartas. Não por falta de matéria restante sobre o tema que viemos trilhando, aqui chegamos ao segundo aspecto de que queremos tratar.

Desde a sua primeira carta a Sena (9 de fevereiro de 1947), Régio manifesta-lhe um tema ao qual voltará algumas vezes ao longo da correspondência e que, antes de vincular-se à esfera do propriamente literário, nos dá uma pauta de sua abordagem humana, inter-pessoal. Refiro-me à sua chamada de atenção - não encontro melhor termo - a Sena sobre o seu temperamento. Cito a passagem:

Quando conversarmos lhe direi que só me desagrada, às vezes, nos seus escritos, um tom de azedume, desconfiança, não sei quê, que acho impróprios dum rapaz que ainda não vi ter razōes de queixa contra a Natureza ou o Destino. (p. 30)

Moto contínuo, de maneira ou cândida ou ardilosa, escreve a Sena algo lapidar: "Em mim, tenha confiança", um enunciado de 
grande poder se considerado no contexto de qualquer diálogo intergeracional.

De fato, creio que o apelo causou efeito e que Sena teve confiança em Régio. Num primeiro momento, já uma semana depois de escrita a carta a que nos referimos, responde com uma longa missiva que hoje pode ser lida como uma autobiografia precoce e condensada, tanto se esmiúça o mais jovem em narrar ao mais velho as situações familiares e pessoais intimas que, infere-se, justificariam o seu tal "não sei quê" de azedo e desconfiado, ou, como dirá depois, de "rangente", nele detectados por Régio. Voltemos um pouco atrás: como lhe corresponde como poeta mais velho, Régio a esta altura da correspondência dá a pauta, e a pauta que estabelece é a da confiabilidade, confiabilidade interpares e, o que é quiçá mais importante, entre gerações.

Não é necessário dizer que esta pauta lhe permite retomar as suas criticas ou os seus conselhos a Sena, dizendo-lhe na carta seguinte que "quereria eu que o ranger de dentes se não ouvisse tanto, e outras suas qualidades mais nobres, mais luminosas que a propensão para o ressentimento e a desconfiança, tomassem a dianteira” (p. 38). Mas sim, talvéź seja necessário dizer que ela digo, a pauta - só subsistirá ao longo do tempo se aquele que oferece a certeza da confiabilidade se mantiver à altura da sua promessa, tanto quanto se aquele a quem esta se destina for capaz de, também ao longo do tempo, relativizar as instâncias da sua expectativa e não degenerá-las em sentimentos de traições; em resumo, tal e como entre quaisquer vínculos inter-subjetivos, tudo funcionando como se um pacto entre aquele que confla - o "confiador" - $\mathrm{G}$ aquele que assegura a confiança - o "confiável" - tivesse que se desenhar e se manter na relação, independentemente de sua manifestação verbal e, menos, literária.

O fato é que Régio estende desde um início a possibilidade de tal pacto a Sena e que este o aceita. O que quero sublinhar aqui é que me parece que ambos o mantiveram menos pelo interesse su- 
postamente comum de afirmar uma posição semelhante no contexto literário de então, e inclusive menos devido às suas personalidades individuais, que pelo peso simbólico, ético, que o mesmo representava em si. Neste momento, recordemos que este passou por uma prova de fogo à altura em que Sena, já no Brasil, escreve e não manda uma carta a Régio, como apontei antes.

Em 1964, Sena esteve em Araraquara, Estado de São Paulo, dando aulas de literatura portuguesa na recém-criada universidade estadual. Já antes havia sido professor na não menos nova estadual de Assis, cidade da qual, note-se, escreve em 1960 uma das mais saborosas cartas a Régio, que versa sobre a sua experiência brasileira. Se na carta de Assis, depois de elogiar a qualidade do teatro brasileiro vis-à-vis o português, e de exaltar o clima de liberdade moral e politica vigentes, Sena otimisticamente confessa terlhe "valido a pena este salto mortal", para usar as palavras com as quais se refere à sua mudança para o Brasil, na carta não enviada o tom é oposto. Lembremo-nos de que no dia 31 de março daquele ano ocorreu o Golpe Militar no Brasil, que entre outros efeitos teve o de implicar, já em 1966, na mudança de Sena e sua numerosa familia para os Estados Unidos, em busca das garantias à atividade intelectual e de cátedra que o regime instaurado passou sistematicamente a perseguir.

Nessa carta, datada de 20 de abril de 1964, Sena insurge-se contra Régio por ter este ignorado o Golpe Militar e suas possiveis repercussōes numa carta escrita uma semana antes, nos seguintes termos:

[...] Portugal é urh país tão espantoso, que Você me escreve a 12 e nem sequer se interroga sobre o que está acontecendo no Brasil, e sobre se os seus amigos serão ou não atingidos pelo que se passa... Será que não lê jornais, ou os jornais aî não bastam para perceber-se? (p. 171)

Se atẻ aqui tudo soa como uma queixa sobre a desatenção ou mesmo a alienação política de Régio, o caminho pelo qual Sena 
envereda a seguir é muito mais pessoal e agressivo. Sem alongarnos demasiado, frisemos apenas que, depois de acusar a indiferença de Régio em responder o questionário sobre ele e sua obra, Sena resume com amargura a sua situação face à de Régio: "Você feliz, deliciando-se com o muito trabalho que tem por ser monumento nacional, e eu aqui sem saber o dia de amanhã, ou a liberdade de amanhã..." (p. 172). Evidentemente, o que leva Sena a este ex-abrupto é a crise política que o afeta; no horizonte, entretanto, desenhase a consciência da sua diferença - geracional e estética, está bem, mas também, e extensamente, vital -, da qual o seu azaroso nomadismo pode ser visto antes como resultado do que causa.

[...] não faço parte do séquito das suas sombras. Não fui nunca também um jovem poeta a seus pés. Não sou, notoriamente, autor de hagiológios. E você, apesar do desprezo que tudo isto lhe merece, é disto que não deixa de gostar”, extravasa mais adiante ( $\mathrm{p}$. 173). E pergunta a seguir: "Guer ou não quer lealmente colaborar comigo?", referindo-se precipuamente à questão do já citado questionário mas também, indiretamente, voltando ao tema que ressaltamos, ao trazer à baila, até nesse momento de azedume total, o pacto pré-existente.

De maneira significativa, a carta de 20 de abril de 64 ficou sem assinar. Escreveu-a, ao que parece, mesmo para não a mandar; antes do que como um tosco - ou "agreste", como qualifica Mécia de Sena - desabafo, poderiamos dizer: escreveu-a para um destinatário já introjetado, para um destinatário que já se havia tornado tão modelar, para bem ou para mal, que se havia erigido, por isso mesmo, em algo indispensável. Talvez pudéssemos pensar que Sena tenha escrito essa carta para si mesmo. Se tivesse pensado no futuro e em seu lugar nele, provavelmente a tivesse autografado, crer-se-ia. São todas estas hipóteses meras suposições. De minha parte, penso que escreveu-a para respeitar o pacto, para vêla escrita e sentir-se incapaz de mandá-la, sequer de assiná-la, e 
isto me parece que não simplesmente, como se dirá, por respeito às frágeis condições físicas ou emocionais de Régio à época.

O fato é que Sena não mandou a carta e, dessa maneira, não arriscou desrespeitar ou romper o limite ético, que era mais importante que as acusações, fundamentadas ou não, sobre a própria atitude ética do destinatário, no que tangia aos seus relacionamentos com outros poetas de menor idade. $\mathrm{E}$ tal limite não o poderia traduzir eu melhor do que com a noção de pacto silencioso de confiança mútua.

Melhor dizendo e para terminar, para afirmá-lo refêz a carta em questão de dois meses e a 7 de junho a mandou a Régio, prenhe de todos os tópicos que recheavam a não-enviada, agora bem menos "agrestemente" desenvolvidos. Mas aqui já nos afastamos do nosso ponto de interesse.

A ameaça de rompimento fora devidamente superada. $O$ poder da palaura de Régio, escrita havia quase vinte anos, seguia vigente, capaz de neutralizar o peso das fraquezas que Sena passara a identificar não só em sua obra mas também em sua pessoa.

ABSTRACT: The sizable correspondence between José Régio, the founder of the movement of "presença", and Jorge de Sena, one of the most significants Portuguese intellectuals of mid-XX century, helps to understand the inter-generational dynamics in the context of Portuguese poetry after Modernism. This essay focuses on the aesthetic and informational differences among the parts and signals, in the context of modern Portuguese literature, one form of transmission of the literary values that shape the relation between them, in which the weight of the word uttered by the older part imply the reactions of the younger one, in despite of his reactions expressed in a letter sent from Brazil in the height of the crisis of the 1964 military coup. Thus, the recent historical background in Portugal and in Brazil offers a privileged standpoint to the analysis of the relationship between Régio and Sena, and between the 
Costa, Horácio. Aspectos da correspondência entre Jorge de Sena e José Régio

"presencistas" and the following generation of Portuguese intellectuals, which tended to be critical of them.

KEYWORDS: Modern Portuguese poetry; inter-generational bonds in Portuguese intelligentsia; political-cultural relations between Portugal and Brazil; epistolary analysis. 